\title{
Abará, Caruru e Vatapá: a influência da culinária africana na formação da identidade brasileira
}

\author{
Abará, Caruru e Vatapá: la influencia de la cocina africana en la \\ formação de la identidad brasileña \\ Abará, Caruru and Vatapá: the influence of african cuisine in the \\ formation of brazilian identity
}

\section{Hudinilson Kendy de Lima Yamaguchi ${ }^{1}$}

Tatiana do Santos Sales ${ }^{2}$

\begin{abstract}
Resumo
O Brasil sofreu grandes influências culturais dos povos africanos a exemplo da culinária, das crenças e dos costumes. Assim, ao considerar a relevância da culinária de raiz africana, como uma influenciadora da formação cultural brasileira, o objetivo desta foi de rever as principais influências epistemológicas da culinária africana na formação da identidade do Brasil. Esta pesquisa é baseada na metodologia indutiva, qualitativa, analítica e descritiva, a partir da revisão bibliográfica extraída de literatura especializada em consulta a artigos científicos selecionados nas bases de dados, Google Acadêmico. Foram utilizados como descritores os seguintes termos: Culinária, Africana, Influência, Cultura e Miscigenação. Foram selecionados e escolhidos vinte e sete artigos para elaboração de estudo, os quais não foram delimitados recortes temporais, todos na Língua Portuguesa. Ao refletir sobre as manifestações culturais presentes no arcabouço culinário dos povos africanos, fica evidente a influência da culinária africana nas relações e aspectos econômicos, educacionais e sociais. E assim concluímos que os africanos tiveram papel importantíssimo no processo de construção da identidade brasileira, e a influência da culinária africana está presente no cotidiano brasileiro.
\end{abstract}

Palavras-Chave: Culinária; Africano; Cultura; Identidade Brasileira.

\section{Resumen}

Brasil ha sufrido grandes influencias culturales de los pueblos africanos, como la cocina, las creencias y las costumbres. Por lo tanto, al considerar la relevancia de la cocina africana, como influyente de la formación cultural brasileña, el objetivo de esto fue revisar las principales influencias epistemológicas de la cocina africana en la formación de la identidad de Brasil. Esta investigación se basa en la metodología inductiva, cualitativa, analítica y descriptiva, basada en la revisión bibliográfica extraída de literatura especializada en consulta con artículos científicos seleccionados en las bases de datos, Google Scholar. Los siguientes términos se utilizaron como descriptores: cocina, africano, influencia, cultura y mestizaje. Se seleccionaron y seleccionaron 27 artículos para la elaboración del estudio, que no se delimitaron en plazos, todos en portugués. Al reflexionar sobre las manifestaciones culturales presentes en el marco culinario de los pueblos africanos, la influencia de la cocina africana en las relaciones y aspectos económicos, educativos y sociales es evidente. Y así concluimos que los africanos desempeñaron un papel muy importante en el proceso de construcción de la identidad brasileña, y la influencia de la cocina africana está presente en la vida cotidiana brasileña.

Palabras claves: Aproximadamente cinco palabras claves o frases en orden alfabético, separados por punto y coma.

\footnotetext{
1 Mestrado em Engenharia; Instituto Federal de Educação, Ciência e Tecnologia do Amazonas; Manaus, Amazonas, Brasil; hkendy@ifam.edu.br

${ }^{2}$ Especialização em História, Cultura Africana e Afrobrasileira; Instituto Federal de Educação, Ciência e Tecnologia do Amazonas; Manaus, Amazonas, Brasil; tatiana.s.salles@ hotmail.com
} 


\begin{abstract}
Brazil has suffered great cultural influences from African peoples, such as cuisine, beliefs and customs. Thus, when considering the relevance of African cuisine, as an influencer of Brazilian cultural formation, its objective was to review the main epistemological influences of African cuisine in the formation of Brazil's identity. This research is based on the inductive, qualitative, analytical and descriptive methodology, from the bibliographic review extracted from specialized literature in consultation with selected scientific articles in the databases, Google Scholar. The following terms were used as descriptors: Cuisine, African, Influence, Culture and Miscegenation. Twenty-seven articles were selected and chosen for the elaboration of the study, which were not delimited in time frames, all in Portuguese. When reflecting on the cultural manifestations present in the culinary framework of African peoples, the influence of African cuisine on economic, educational and social relations and aspects is evident. And so we conclude that Africans played a very important role in the process of building Brazilian identity, and the influence of African cuisine is present in Brazilian daily life.
\end{abstract}

Keywords: Cooking; African; Culture; Brazilian Identity.

\title{
1. Introdução
}

O hábito alimentar de uma civilização reflete a sua identidade social, forjando sua identidade e influenciando na construção de diversos elementos sociais e econômicos. Os estudos de Da Silva (2014) apontam que metade da população brasileira é negra ou parda, influenciando diretamente na construção da cultura brasileira.

É possível observar a influência deles na culinária, indo desde um simples prato de comida, passando pelas músicas, pinturas, educação, agricultura e chegando na religião. Essa cultura, também denominada de afro-brasileira, tem estado presente no nosso dia a dia, o estilo culinário é próprio, marcadamente e tem como marco influenciador o azeite de dendê e demais produtos de origem africana.

A relação dos povos quilombolas com o alimento vai muito além do observável, pois o alimento representa a resistência, a devoção e a fartura das comunidades negras rurais, "[...] é por meio do alimento, e através da forma de cultivar, de preparar e de oferecer os alimentos, que eles guardam os saberes, as memórias, subjetividades e simbolismos." (SILVA, 2019, p. $31)$.

No Brasil, Dos Santos (2011) traz o tema da cozinha e da mesa regional brasileiras influenciadas pelos contornos africanos que remetem à memória gustativa, dando verdadeiro salto cultural de uma riqueza étnica e cultural. Com início na colonização, até os dias atuais, pode-se detectar a presença do tempero africano participando ativamente da formação da nossa nação e construção da nossa identidade.

Esta revisão de literatura tem por justificativa a contribuição para reflexões sobre a influência da culinária africana na formação cultural, social e econômica do Brasil, ampliando 
discussões nessa temática. Tem como objetivo investigar a influência africana na formação brasileira.

O artigo está estruturado em oito tópicos, iniciando pela introdução, contextualizando a temática. O segundo tópico apresenta a Etnografia Cultural Brasileira a partir das contribuições da raça negra para o processo de miscigenação do país. O terceiro e quarto tópicos descrevem a culinária africana e a sua importância, sendo elevada à condição de patrimônio imaterial. No quinto tópico, é descrita a influência da culinária nos arranjos produtivos da agricultura e pecuária. A importância da culinária é descrita no sexto e sétimo tópicos como referência para a moda e a musicalidade. No oitavo, e último tópico, é descrita a importância simbólica da comida Votiva Africana para a religiosidade de matriz Africana.

\section{Metodologia}

Para a realização da revisão bibliográfica proposta, foram eleitos artigos, dissertações, teses e trabalhos publicados ou apresentados em reuniões científicas com a temática de cultura afro-brasileira. Para isso, foi feita uma busca de artigos nas seguintes bases de dados: Google Acadêmico e Scielo, sendo que as referências duplicadas foram excluídas.

A abordagem metodológica é qualitativa, classificada como pesquisa teórica descritiva/explicativa do Estado da Arte, cujo procedimento de revisão bibliográfica volta-se para "a exposição resumida das principais ideias já discutidas por outros autores que trataram do problema, levantando críticas e dúvidas." (GERHARDT; SILVEIRA, 2009, p. 66), conforme recomenda Gomes (2004), que sejam analisadas e revisadas as pesquisas historiográficas com o objetivo de analisar e discutir as influências epistemológicas da culinária africana na formação da identidade cultural do Brasil, conforme orienta Silva; Ribeiro (2014); Andrade (2018) e Lakatos; Marconi (2019).

Assim sendo, selecionaram-se artigos sem limite temporal e, como a pesquisa limitouse à produção brasileira, foram elencados somente artigos nacionais. Os descritores utilizados foram as palavras "cultura; culinária; influência; africana e/ou afro-brasileira". Como critério de exclusão não foram considerados os artigos publicados em revistas sem indexação ou sem contribuição para a pesquisa.

A investigação étnica de formação do povo brasileiro nos remete ao início dos movimentos coloniais do século XV, com a chegada do povo europeu e dos negros. Estes povos, juntamente como os indígenas, foram, segundo Alves; De Carvalho e Coelho (2018), responsáveis pela construção da identidade do povo brasileiro, contribuindo para o processo 
de construção dos Estados-nação com uma realidade mais pluricultural. Esta compreensão cultural é definida por Reale (2017) como uma marca impressa na alma coletiva de um povo e nela se refletem seus símbolos, valores, sentimentos, necessidades, inspirações e desejos.

\section{Etnografia Cultural: As contribuições africanas para miscigenação brasileira}

A cultura popular brasileira vem sendo analisada nas ciências sociais a exemplo das discurções de Mira (2017) onde a autora relata em sua obra que a matriz africana influenciou de forma significativa para nossa formação cultural, através das diversas manifestações e concepções dos agentes sociais, apoiando-se no contexto antropológico, onde a cultura é entendida como a construção histórica do conjunto de crenças, ideias, valores, aspectos morais e os produtos de um grupo humano (PÉREZ, 2009). E assim se define a multiculturalidade do Brasil este país que marcado pela:

[...] multiplicidade de culturas étnicas que participaram da formação de nosso povo, a identidade cultural brasileira resulta da miscigenação de costumes, de formas de pensar, em face do processo civilizatório, dos avanços da ciência e mais atualmente dos acessos às novas tecnologias (LONTRA, 2017, p. 298).

Para entendermos os porquês culturais é necessário estabelecer um diálogo com as memórias do passado, relacionando-as com o presente (CASTRO, 2017) e compreender que a cultura não é algo com começo, meio e fim, e sim um processo histórico de interação contínua entre pessoas, onde cada uma destas manifestações é influenciada por grupos sociais distintos. A exemplo da cultura: europeia e africana que chegaram no Brasil no período colonial e se miscigenaram com a tradição indígena local, formando um país de muitas culturas e nações, motivo pelo qual encontramos diversas manifestações artísticas, folclóricas e culturais (DOS SANTOS, 1998).

A partir dos estudos de Azevedo (1971), percebemos que a cultura não diverge do biológico, o autor discorre para uma concepção onde a cultura, nas suas múltiplas manifestações, é a expressão intelectual de um povo, não só reflete as ideias dominantes em cada uma das fases de evolução histórica, na civilização de cuja vida ele participa, como mergulha no domínio obscuro e fecundo em que se elabora a consciência nacional.

Os povos de matriz cultural africana influenciaram literalmente em todos os campos 
sociais da formação de uma sociedade, Santos (2017), descreve a importância das manifestações culturais como: a arte, a música, a dança, a religião e a culinária, que influenciaram e contribuíram para construção de uma sociedade culturalmente conhecida como a nação mais miscigenada e multicultural do mundo devido aos diversos povos e culturas que tramitam em terras brasileiras.

A formação da identidade do povo brasileiro está alicerçada em raízes culturais e na herança biológica trazida pelo povo africano. Para Nascimento (2020), este processo de miscigenação da cultura popular brasileira imprime, até hoje, fortes influências culturais e produz uma variedade de manifestações culturais e contribuições para diversidade cultural e identidade do povo brasileiro.

O processo de formação cultural brasileira, de acordo com Ferreira (2018), começou a ser impregnada no contexto social do Brasil com a chegada dos africanos, oriundos e intermediados pelo apogeu dos colonizadores durante o tráfico de escravos, servindo de mão de obra nos campos de produção e nas casas dos senhores europeus, porém trouxeram consigo uma grande diversidade cultural e social de várias regiões da África. Esta diversidade multicultural é relatada por Leme (2015), em sua pesquisa, autora afirma que heterogeneidade cultural é uma prática cultural distinta, e que em alguns aspectos, ela se caracteriza pela diversidade de diferentes culturas históricas, porém os africanos incorporaram algumas práticas europeias e indígenas, que os influenciaram culturalmente.

Esse intercâmbio cultural, segundo Lima (2010), contribuiu para uma formação cultural afro-brasileira híbrida e peculiar que perdura até hoje no Brasil, tendo como uma das principais influências culturais a cozinha africana, que foi introduzida no Brasil pelo sistema de escravidão, e contribuindo significativamente para formação da cultura brasileira.

\subsection{A culinária da África nos pratos brasileiros}

Dentre as muitas contribuições da cultura negra para formação da cultura local, Lody (2019), em sua obra o Coco, descreve a influência de diversos ingredientes usados até hoje na culinária brasileira como: o leite de coco, a pimenta malagueta, o gengibre, o milho, o feijão preto, as carnes salgadas e curadas, as ervas aromáticas e o próprio azeite de dendê. $\mathrm{O}$ autor relata ainda que foram introduzidos diversos tipos de comidas pelos escravos como: o vatapá, o caruru, o abará, o acarajé, o bobó, o angu, o cuscuz de milho, a moqueca de peixe e a 
feijoada brasileira, além dos diversos quitutes como: a canjica, o quindim, a pamonha, a tapioca e o bolo de milho.

A culinária tradicional, segundo Muller; Amaral e Remor (2010), está sempre associada aos hábitos de alimentação de um povo, e este elemento cultural de representação materializa as particularidades e vivências de um povo, marcada pelas especificidades geográfico-culturais, a exemplo dos alimentos que:

[...] envolvem os mais diversos significados, versa que este envolvimento está desde o âmbito cultural até as experiências pessoais, impregnados de significados e culturalmente determinados nas práticas alimentares, que vão dos procedimentos relacionados à preparação até seu consumo propriamente dito, a subjetividade veiculada inclui a identidade cultural, a condição social, a religião, dentre outros simbolismos (GARCIA, 1994, p. 1).

No entendimento de Freyre (2006), a nossa herança cultural africana é visível na cozinha, na mesa, na linguagem, na religião, nas canções, nas danças, dentre outras. E desta vasta manifestação cultural, refletiremos sobre o processo de alimentação como um dos fatores preponderantes da cultura africana, sendo cada vez mais valorizado por elementos diversificados que refletem na ação dos sujeitos que geram mudanças no ambiente natural e social em que se encontram.

No contexto brasileiro atual, Santos (2012) relata uma variedade de pratos oriundos e influenciados pela culinária africana, contudo, na tentativa de compreender um pouco mais da história alimentícia cultural em torno de um prato simbólico que represente a cultura africana, debruçamo-nos sobre as seguintes iguarias: o abará, o caruru e o vatapá como parte constituinte da identidade brasileira.

Este estudo parte do pressuposto que o ato de se alimentar está permeado de significados históricos, contribuindo para cultura e imprimindo a sua identidade. Lima, Ferreira Neto e Farias (2015), endossam afirmarem que a formação da cultura identitária do povo brasileiro, foi forjada a partir de uma miscelânea de contribuições, e as confraternizações sociais presentes neste processo, transmitiram valores culturais de raízes, reforçando as relações afetivas e alimentares do povo brasileiro.

A alimentação brasileira recebeu grandes influências africanas, já que vários dos alimentos foram trazidos da África, dos quais imperam o:

[...] azeite de dendê, juntamente com inhames, bananas, pimentas, feijões, 
entre outras delícias, como quiabos e camarões, [...] o que torna o Brasil um enorme caldeirão, convivendo e misturando-se com diferentes e saborosas contribuições gastronômicas (MIRANDA, 2003, p. 70).

Este contexto histórico é descrito por De Lima (2010), que descreve as cozinhas das casas de engenho, onde os alimentos ganhavam o sabor africano com o preparo das escravas negras que elaboravam pratos saborosos com simbologias, esta mistura de temperos e sabores foi adicionada à contribuição de outras duas emblemáticas cozinhas que são a portuguesa e a indígena, gerando novos sabores, construindo novos hábitos alimentares para culinária brasileira.

Em contribuição, Mascarin (2015) relata que o encontro da cozinha africana com a cozinha brasileira, neste encontro de múltiplos temperos, especiarias, frutas, raízes e alimentos, geraram novos hábitos no consumo de alimentos, onde alguns foram mantidos, conforme o costume do africano, já outros enriquecidos com os itens locais como é o preparo e o consumo da farinha de mandioca de origem indígena, enquanto outros mantidos, como o preparo do vatapá.

No Brasil, o vatapá ganhou características e peculiaridades, sendo considerado um dos pratos nacionais de origem africana, que manteve a sua essência em alguns ingredientes característicos, e sendo acrescentados outros alimentos ao seu feitio, aprimorando e realçando seu sabor. Sobre esta iguaria, Cascudo (2004, p. 883) esboça:

O mais famoso dos pratos afro-brasileiros é o vatapá, cozidos de peixe ou de galinha, para este preparo o azeite-de-dendê, a pimenta e o leite de coco são fundamentais. Na Nigéria não há prato especificamente idêntico ao vatapá. O leite de coco não possui lá a presença que usufrui no Brasil. [...] $\mathrm{O}$ mistério da origem do vatapá não exclui a pátria africana ocidental, banto ou sudanesa. [...]. Lógico é sugerir que o pitéu teve desenvolvimento e características na Bahia, vindo em forma mais simples da pátria negra. [...]. O vatapá continua evoluindo, complicando-se na elaboração culinária pela adição e substituição dos componentes (CASCUDO, 2004, p. 883).

Na cultura alimentar brasileira, inúmeros pratos de inspiração portuguesa ou indígena foram modificados pela condimentação ou pela técnica culinária do negro, alguns dos pratos mais caracteristicamente brasileiros são de técnica africana como: a farofa, o quibebe e o vatapá (FREYRE, 2006), e as restrições alimentares impostas aos escravos protagonizaram novos preparos para a atualidade de acordo com a contriuição descrita que:

Apesar da existência de um cardápio para os escravos, mais restrito do que o dos donos das fazendas, com elementos proteicos à base de leite. Entre as comidas preferidas pelos escravos para "adoçar a boca" e que continuam a 
ser apreciadas hoje, o estudioso potiguar cita o caldo de cana, o bolo-preto, o pé-de-moleque, a rapadura, o doce seco, o arroz doce e o doce de coco com açúcar bruto, todos com origem africana (CASCUDO, 2004, p. 126).

Assim, a contribuição da culinária negra para o Brasil vem desde o período colonial até os dias atuais, valorizando os sabores e saberes africanos, pois é necessário não somente comer, mas analisar, identificar e vislumbrar todas a contribuições múltiplas de aroma, textura e cor, que fazem uma explosão nos sentidos, envolvendo-nos nesta rica e criativa cozinha afrodescendente, que leva status de patrimônio nacional brasileiro.

\subsection{Culinária e o Patrimônio Imaterial}

Os sabores dos temperos e da culinária que embarcaram nas caravelas com os africanos contribuíram a favor da cultura de todas as regiões brasileiras, principalmente no Nordeste que é rico em sua gastronomia de influência afro-brasileira, ganhando aromas e sabores em doces, salgados e quitutes, cada um com o toque de criatividade do cozinheiro que o deixa mais apetitoso.

O acarajé, o quibebe, o caruru, o abará e o bobó, relatados por Saraiva (2016), são alimentos de origem africana, dos povos Jeje, Angola e Moçambique, esses quitutes preparados, aqui no Brasil, eram preparados pelas escravas africanas, permitindo a propagação da influência africana na alimentação. O caruru, segundo Khatounian (1994), foi muito difundido no Norte e Nordeste, onde os escravos impuseram o sabor inconfundível da cozinha africana.

Através da arte de cozinhar, as mulheres negras conseguiram perpetuar tradições culinárias repassadas de geração em geração no interior das casas nas quais trabalhavam, utilizando, segundo Batalha e Silva (2015), os restos e sobras, pois não havia reservas suficientes para eles. Assim as práticas culinárias, que foram desenvolvidas no Novo Mundo, são respostas culturais adaptadas a uma nova situação à imagem do destino do africano trazido para o sertão que, ao comer, tenta reencontrar um gosto que lembra sua terra natal.

Os modos culinários colocam, na visão de Bourdieu (1979), em ação os saberes e técnicas do cotidiano, e, assim, as cozinheiras negras incluíam elementos da culinária afrobrasileira na dieta dos seus patrões, e esta troca de conhecimentos entre "patroas e cozinheiras possibilitaram uma transformação da vida dessas mulheres que, não só se profissionalizaram, 
mas também introduziram um tempero africano nos gostos alimentares dos moradores das casas grandes [...]" (CAVIGNAC; SILVA, 2019, p. 36), consolidando um novo regime alimentar brasileiro:

[...] a contribuição africana afirmou-se principalmente pela introdução do azeite de dendê e da pimenta malagueta, ingredientes tão característicos da cozinha baiana; além da introdução do quiabo; pelo maior uso da banana nos preparos e pela grande variedade na maneira de se preparar a galinha e o peixe (FREYRE, 2006, p. 542).

Outra característica marcante do patrimônio imaterial da culinária africana no Brasil é a incorporação de novos hábitos alimentares com o consumo do angu, cuscuz, pamonha e a famosa feijoada brasileira, (CASCUDO, 2004) cuja origem está relacionada à inspiração do cassoulet francês, que ser trata de um ensopado de feijão branco com linguiça de porco e carne de pato, (BRAUNE, et al. 2017) e nas "senzalas dos grandes engenhos de cana-deaçúcar, onde os escravos acrescentavam ao caldo de feijão preto, concedido pelos senhores, restos de carne, principalmente de porco, como orelha, pé e rabo.” (FERREIRA, 2017, p. 60) "sendo acrescidos temperos e pimentas e preparadas em panelas de barro e de colheres de pau." (DA SILVA, 2014, p 31).

Outra iguaria de origem africana, que teve o seu reconhecimento patrimonial brasileiro, é o acarajé, que é um bolinho de feijão fradinho, cebola e sal, frito em azeite de dendê (LODY, 2002) e sua etimologia:

[...] é a variação linguística dos dois termos: acará que é "bola de fogo" e jé do verbo "comer", ou seja, comer bola de fogo. O acarajé, enquanto símbolo da cultura afro-brasileira, foi tombado desde 2004, alçando o status de bem imaterial, registrado no "Livro dos Saberes" do Instituto do Patrimônio Histórico e Artístico Nacional (BOTELHO; SANTOS, 2016, p. 140).

Em contexto contemporâneo, a comida e seus processos e significados ganham destaque no entendimento dos patrimônios imateriais, que cada vez mais buscam recuperar memórias, para preservar os saberes e os lugares como representações singulares da nossa cultura.

\subsection{A Comida Africana Contribuindo para Educação no Brasil}


A utilização da culinária no processo de compreensão e aceitação da negritude a qual se mostra como uma metodologia de aplicabilidade da lei $10.639 / 03$, na perspectiva proposta por Brasil (2003), traz um olhar sobre a África mais positivo, de modo a demonstrar sua riqueza cultural e colocando os negros também como agentes do processo histórico e cultural do Brasil.

$\mathrm{O}$ ato de ser alimentar, reúne as pessoas, e apresenta-se como elemento de conexão e compreensão da diversidade étnica e miscigenada do Brasil, tendo o seu reconhecimento multicultural dos povos e contribuição da cultura africana e afro-brasileira presentes no cotidiano dos alunos, que muitas vezes nem são percebidas.

A comida africana vai bem mais além da mesa, pois os saberes e sabores são utilizados como instrumentos pedagógicos articulados à perspectiva educativa crítica, proporcionando uma incursão e articulação de aspectos fundamentais à população negra e às comunidades tradicionais (COSTA, et al., 2019). O fortalecimento da identidade cultural e da consciência racial, além de valorizar as dimensões da vida econômica, social e cultural popular culturais, reestabelece várias conexões e vínculos afetivos, sejam eles familiares e/ou comunitários, contribuindo para o sentimento de igualdade e combate ao preconceito racial e religioso. (GUILHON, SALAS, 2016).

$\mathrm{O}$ alimento e seus sabores são elementos mediadores do processo de ensino e aprendizagem, para o processo educativo na Educação de Jovens e Adultos - EJA, "por inúmeras vezes, não se verbalizam em sala de aula, oferecendo a possibilidade da construção coletiva de um banquete que priorize a pluralidade, a diversidade, a autonomia e o protagonismo desses sujeitos." (COSTA, et al., 2019, p. 92).

A gastronomia africana é como "um recurso lúdico aplicável à discussão sobre conceitos como atrativo cultura material, imaterial e patrimônio, na forma de um jogo de tabuleiro. Parte-se, portanto, do entendimento do patrimônio cultural gastronômico como fonte educativa, em um processo experiencial de apropriação, identificação e (re) conhecimento que pode gerar um efeito multiplicador de atratividade." (OLIEIRA, 2020, p. 42).

As iniciativas educacionais desta natureza levam ao conhecimento culinário e à aprendizagem dos alunos, através de fontes de discussão sobre a valorização da cultura e dos saberes desses sujeitos, com vistas a aprofundar os conhecimentos (extra) curriculares, sendo o lúdico importante para que as crianças possam expressar os seus sentimentos em relação ao 
mundo social. Como eles gostam dessa prática pedagógica, há o incentivo ao envolvimento e ao trabalho em grupo com a abordagem de conhecimentos históricos, sociais e culturais.

A EJA é uma modalidade de ensino que possui muitos desafios dada a peculiaridade do seu público (PARDIM, CALADO, 2016; MEDEIROS, DA FONTOURA, 2017; RIBEIRO, 2019), sendo necessárias ações motivadoras, criativas e paradidáticas para buscar facilitadores de aprendizagem destes alunos, como proposta Balduíno, Souza e Silva (2014) articulam temas de inclusão digital com a instrumentação cultural da culinária africana, tema que foi discutido de forma criativa e prazerosa, aliando a culinária africana à matemática e à história de vida.

Conhecer a cultura africana através de sua culinária possibilita aos alunos, além da ampliação dos conhecimentos, também a formação de conceitos em que o respeito, a aceitação e a admiração possam fazer parte do convívio social de cada indivíduo. Conhecer, aprender e respeitar as diferenças dependem do acesso que as pessoas têm em relação às experiências culturais, quanto mais existir contato com diversas experiências culturais, maior será a aceitação das diferenças existentes, principalmente no contexto escolar, onde nos deparamos com muitos conflitos por conta da grande diversidade cultural.

O jogo Mancala, descrito no trabalho de Da Silva (2018), é da família dos tabuleiros, tem sua base no processo de semeaduras, que remete a grãos da culinária africana cuja ideia implementada no processo de aprendizagem aos estudos africanos permite o desenvolvimento de potencialidades para o conhecimento e desconhecimento da história e cultura africanas.

\subsection{A Comida influenciando na agricultura do Brasil}

A participação dos negros africanos no Brasil Colonial aconteceu a partir do momento em que a experiência colonial portuguesa estabeleceu a necessidade de muitos trabalhadores para ocuparem as grandes fazendas produtoras de cana-de-açúcar. Da Silva (2019) relata que a mão de obra em sua maioria formada por escravos negros, iniciavam nos canaviais, passando pelo engenho até o processo de encaixotamento para exportação do açúcar.

O negro africano não contribuiu somente com a sua mão de obra nas produções agrícolas do período colonial, eles trouxeram consigo, da África, o conhecimento da utilização de elementos naturais em sua crença, onde "a terra une as pessoas para plantar, colher e lutar pelo território e o alimento, que vem da terra, une as pessoas nas celebrações." (SILVA, 2019, p. 48). 
Outra valiosa contribuição do povo africano, sobre o uso da culinária através dos preparos de plantas, trazidas da África, foi a produção de xaropes, tônicos e infusões, Silva (2018), descreve a utilização destas ervas associadas aos conhecimentos sobre os elementos da natureza na medicina caseira, dando destaque ao uso das nzaba nzambiri - folhas sagradas (tradução nossa). Outros saberes utilizados pelo povo africano no Brasil é a utilização das folhas do abacateiro (Persea americana) em efusão no combate a dores reumáticas e a gota, e o uso do abacaxi (Ananas sativus) como expectorante e digestivo. (SCISÍNIO, 1997).

Os elementos africanos foram fundamentais para formação cultural do Brasil, onde podemos destacar: o uso de pimentas e temperos africanos na culinária; o samba de roda para musicalidade e os turbantes, grafismo e acessórios multicoloridos para o vestuário. Estas "tradições locais, crenças e formas de se comunicar dos vários grupos africanos trazidos na condição de escravos para terras tão distintas os acompanharam [...]” (MORAES, 2017, p. 6).

Muitos destes ingredientes e costumes foram trazidos para o Brasil junto com os escravos, no processo de tráfico negreiro, como é o caso da banana (Musa spp), ícone de brasilidade mundo afora (DA SILVA, 2014), e as receitas tradicionais do vatapá, do acarajé, do caruru:

[...] que utilizam condimentos provenientes da África para sua elaboração revelam não só a forte presença africana na culinária dessa parte do Brasil, mas também a intensa troca comercial de produtos realizados entre o Brasil e o continente africano no período colonial (BOTELHO, 2010, p. 64).

Os africanos faziam grande uso dos derivados da mandioca, como a farinha, a goma e o polvilho, assim como a rapadura e o fubá. Estas influências da culinária afrodescendente no Brasil marcam e determinam sua importância na implantação de culturas como o dendezeiro (Elaeis quineensls), que é um grande símbolo da África, esta palmeira:

produz cachos generosos, tendo por média de duzentos cocos por cacho. Desta palmeira tudo é aproveitado, a madeira para construção de casas, as fibras para a sua cobertura. E por isso é chamada na África de a árvore do paraíso. No Brasil, o azeite de dendê proporcionou a criação de novos sabores, e dá aos pratos uma estética peculiar, trazendo nova identidade à mesa como é o caso da farofa, que é uma realização genuinamente brasileira. Esta iguaria nacional, no período conlonial, alimentou tanto os senhores e escravos (LODY, 2018, p. 20). 
Este processo de inclusão das influências africanas na formação da cultura agrícola do Brasil dá-se pelas características presentes em grande parte do continente africano por possuir um clima tropical, com faixas equatoriais (LONGHURST; PAULY, 2007), fator que favorece a introdução e adaptação das espécies nativas aqui no Brasil, como é o caso do dendezeiro. Esta palmeira e os outros diversos frutos, tubérculos e condimentos foram importantes para construção da identidade de nossas cozinhas, bem como na formação de um diverso acervo agrícola de matriz africana no Brasil. Assim, neste entendimento plural sobre comida e cultura agrícola do Brasil, constituem-se elementos que foram e são cultivados a partir desta influência.

\subsection{O que vestimos influenciados pela comida africana}

Dentre os sincretismos religiosos de influência africana associados à culinária, é importante falar sobre os hábitos que foram incorporados às cozinhas brasileiras que dizem respeito principalmente ao orixá que é:

O uso do pano na cabeça, a grande higienização, o costume de mulher regrada não entrar na cozinha, assim como abanar a comida da direita para a esquerda e somente mexer para frente, utilizando-se de colher de pau e panela de barro e essas são algumas tradições que foram incorporadas ao costume brasileiro (VIDAL, 2015 apud MORAIS, 2017, p. 11).

A personificação do ícone da figura da mulher africana é a baiana, com suas roupas exuberantes e alegres, assim a roupa da baiana "é a denominações dada ao traje de matriz africana que aponta e reúne os elementos visuais do barroco europeu” (LODY, 2018, p. 30), que traz em sua composição um grande volume nas saias, cores exuberantes e marcantes, texturas nas fitas, rendas e bordados, além da tecnologia vernacular presente nos panos africanos, tecidos tradicionalmente produzidos artesanalmente em tear manual.

O autor complementa a caracterização ao relatar que a indumentária baiana está regada de simbolismos e influências culinárias, personificando os múltiplos papéis sociais da mulher com vinculação a diferentes manifestações de matriz africana.

Quanto à composição e ao significado das simbologias utilizadas na moda afrobrasileira, remete-se ainda ao colorido alegre das estampas criadas por uma tipografia própria, Crioula, cheia de significados e valor cultural, sempre relacionadas com as cores da África, 
"presentes no colorido e sabores da culinária africana, dando sentido nítido a quantidade de informações exploradas" (MORAIS, 2017, p. 89) por profissionais de moda que se dedicam exclusivamente a representações étnicas de uma cultura tão rica que originou o brasileiro.

A culinária é um celeiro de contribuições para a moda, proporcionam um material riquíssimo para construir referências tradicionais e contemporâneas no processo de transformação e criação de coleções da moda afro-brasileira, a exemplo das diversas influências transmitidas com base:

[...] na tecelagem, na ancestralidade, na africanidade, na afro-brasilidade, respeitando a questão cronológica dos negros no Brasil, a solidariedade e o cotidiano. Podendo ter a impressão de serem meras estampas, mas ao manter a visão mais profunda é possível notar que cada elemento faz referência a uma história, um símbolo da ancestralidade, do cotidiano, da culinária ou da religião que estão ao mesmo tempo dentro de um contexto relacionado a afro-brasilidade (LOPES; FALCON, 2010, p. 104).

Ao manter esta identidade como conceito principal, percebe-se que a moda, "embora receba influência dos elementos simbólicos desta matriz, pode ser usada por qualquer grupo social que se identifique com suas roupas ou seus acessórios, sendo efetivamente uma moda para todos" (HARGER, 2016, p. 119). As vestimentas afro-brasileiras nascem da mistura da cultura brasileira com a africana, "a partir de elementos visuais, sonoros e mesmo comidas encontram soluções estéticas e funcionalidades [...] no processo de criação" (LODY 2001, p. 87). E assim constatamos sua grande influência no mundo contemporâneo, já que:

A vestimenta afro-brasileira hoje se encontra como instrumento da construção e recriação não somente da cultura afro-brasileira, mas também da cultura nacional, não a que privilegiava um país miscigenado culturalmente e sufocava e inferiorizava as culturas negras, mas a que construiu um país multicultural, entendendo e respeitando a diversidade étnico-racial aqui existente (LIMA; DA SILVA; CEZAR, 2017, p. 31).

Ao receber grande influência da culinária, a moda afro-brasileira possui estampas coloridas com cores vibrantes, estilo contemporâneo, personificando uma cultura rica e vasta, influenciando novos costumes, estampando um estilo próprio que valoriza uma política de afirmação e identidade cultural.

\subsection{A comida da África dando ritmo e som do Brasil}


Nos gêneros musicais como o samba, batucada e malandro, que são característicos da cultura carioca e das festividades brasileiras com influência negra, é comum retratar os hábitos alimentares e culinária africana, onde são cantados em versos e poesia elementos como acarajé, abará, vatapá e o tempero da baiana, retrato de uma autêntica cozinha brasileira (DE CASTRO NETO; LEITÃO, 2014). Este elo de união constituído pela culinária e pela música fica evidente nos relatos de Gonçalves (2019), onde o autor descreve a união da comunidade afro-brasileira frente aos novos arranjos de referências africanas e que, nestas letras, são encontradas expressões africanas de exaltação ao alimento e além de uma forte menção à pimenta.

Os elementos constituídos pelos traços africanos, a partir da influência da culinária, vão bem mais além da dança, música, religião, arte, culinária e idioma do país, esta contribuição torna-se o cerne da cultura brasileira, tamanha é a influência (MORAES, et al., 2020).

A diversidade cultural presente em nosso país é riquíssima, isso se deve as grandes contribuições dos africanos, pois a cultura brasileira torna-se indissociável às influências trazidas pelos negros africanos, a exemplo da musicalidade e ritmos brasileiros que, ao ser investigada, sempre terá maior ou menor grau da influência da cultura afro-brasileira, podendo ser vistos em qualquer manifestação cultural, pois seu "ritmo forte e cadenciado atravessou o tempo mantendo-se vivo e atuante, proporcionando alegria e entusiasmo às festas de todo país." (MORAES, et al., 2020, p. 7).

Nesse sentido, as africanidades estão representadas em todos os lugares, conectandonos com a cultura africana a partir da comida no processo cultural contínuo. Cantado em verso e prosa, o samba é a nossa maior representação cultural, tornando-se um símbolo da cultura afrodescendente, e sendo um determinante para a identidade musical brasileira, pois:

[...] o samba é merecedor de tal denominação por ter se valido de um passado formador de nação a qual aportou e o acolheu, inicialmente, como um escravo [...] Quanto ao papel da cultura negra na miscigenação como precursora da identidade musical brasileira, não se pode negar que, ter a presença do negro e seus descendentes na história brasileira, o samba não seria o símbolo que é hoje. Logo a cultura com sua religião, musicalidade, culinária e outros aspectos, tiveram muita influência na construção da identidade musical brasileira, sendo o seu maior destaque o samba (DA SILVA, 2017, p. 231-212). 
Os ritmos fortes de influência africana se perpetuaram e se mantêm vivos até os dias atuais. Moraes et al., (2020), relatam que os negros usaram o seu ritmo para levar alegria às festas. Sempre acompanhado de boa comida, os negros buscavam subterfúgios para festejar, mesmo que escondidos dos seus senhores, para manter aceso os seus costumes e rituais.

Outro ritmo de influência negra que se instalou no nordeste do Brasil, e hoje ganhou o mundo, foi o forró, que tem sua origem na palavra Forrobodó, derivação da palavra Bantu, pertencente ao tronco linguístico africano, este ritmo musical está associado "à culinária, baseando-se no cardápio nordestino [de influências negras] como a macaxeira, escondidinho de carne de sol, feijão verde e paçoca." (ALBUQUERQUE FILHO, 2018, p. 46). O forró é cadenciado, retratando a realidade do sertão, moldado para dançar a dois e é uma grande prova que povos africanos deram à música brasileira o melhor de sua musicalidade.

\subsection{Comida de santo assentada nos terreiros e na mesa do Brasil}

A comida junta as pessoas e, no caso da culinária africana, ela recebe estatos de comida Votiva. Nas "representações religiosas de matriz africana a relação com a alimentação tem uma representação do sagrado" (SILVA, 2016, p. 24), pois segue tradicionalmente um ritual aos alimentos oferendados aos santos durante os rituais sagrados, a comida votiva segue as receitas tradicionais, para tanto não existe nenhum mistério no abate praticado nos terreiros, pois as divindades são cultuadas com oferenda de comida preparada com carne e muitos outros ingredientes de preceitos ritualísticos como é o caso do quiabo, pimenta, milho, farinha de mandioca e o dendê (BARROS; PERIN, 2009).

Esta comida Votiva também é a comida cotidiana do africano nas suas terras distantes, só que, naturalmente, quando a comida é de sacrifício ou é de oferenda, ela é praparada como mais esmero e requinte, desta forma:

[...] o que torna a "comida de santo" africana é muito menos os ingredientes que entram na sua preparação, mas um conjunto de técnicas transmitidas de forma iniciática e secreta, somadas às visões de mundo evocadas através da comida, os significados, os sentidos, os sentimentos, o Sagrado construído e reconstruído a todo momento a partir da experiência histórica de cada comunidade. Assim, se aceitarmos que esta cozinha ritual é afro-brasileira, fugimos ao menos da busca pela pureza e nos tornamos mais abertos para entender a dinâmica do pensamento africano, dinamismo este que permitiu, ao lado de permanências africanas no Brasil, recriações e invenções feitas não de forma aleatória, mas fiéis a visões de mundo postas a prova em cada indivíduo na diáspora negra pelo mundo (SOUSA JUNIOR, 2011, p.100). 
Estes preparos senguem uma tradição na cultura afro-brasileira onde cada orixá tem a sua preferência alimentar. Daí a existência dos ritos e rituais na confecção dos seus alimentos, seja nos prazos estabelecidos de privação para tornar a ingerir o alimento, na escolha de quem vai prepará-los, ou até mesmo no conteúdo dos pedidos no momento do oferecimento daquele alimento. A exemplo das predileções dos santos temos "o acaçá, que é massa a base de milho branco, sem tempero, cozido no vapor envolto na folha de bananeira, conhecido como comida de Iansã” (MENDONÇA, 2015, p. 6); o amalá de Xangô, o abará Oxalá e o Caruru, que são comidas Votivas oferecidas para os orixás Ibeji e Xangô.

No rol das chamadas "comidas de azeite", o acarajé é um dos alimentos ritualisticos do candomblé, que não ficou restrito apenas às oferendas a Iansã, mas alcançou as ruas de Salvador, nas festas profanas, chegando, até mesmo, às praias da cidade. E o acarajé das ruas é considerado "quente" quanto acrescenta-se pimenta ao seu recheio. As pimentas, assim como o azeite de dendê, também são condimentos essenciais de uma cozinha marcada pelas cores vibrantes e cheiros peculiares (SANTOS, 2012, p. 2).

Desta forma, ratificar a grande influência da alimentação trazida e adaptada pelos povos da África seja para a nutrição do corpo, quanto para a manutenção dos elos espirituais através dos ritos religiosos do Candomblé, ou da Umbanda, é apenas o limiar de tais entendimentos, já que essas "expressões de fé possuem em si os alimentos e a alimentação como sua base teológica. Embora existam vários trabalhos apontando sobre o objeto de pesquisa, muito há a emergir sobre o assunto, nesse sentido o trabalho prossegue." (SILVA, 2016, p. 25).

Esta influência, que outrora era somente para as representações dentro dos ritos candomblecistas, umbandistas ou juremeiros, passou a fazer parte das festas de santos católicos, (DO VALE, 2013) constituindo um processo de integração, em torno dos quais toda a comunidade quilombola se mobiliza em prol do fazer alimentar, prestando homenagem aos santos de devoção da família e/ou aos padroeiros daquela comunidade, com demonstrações de fé, comunhão, agradecimento e uma perpetuação dos costumes herdados de nossa ancestralidade afro-catolicista. Sendo uma forma de manter as tradições:

[...] através do respeito aos mais velhos detentores da experiência tradicional em tocar instrumentos, cantar rezas e louvores, tudo é feito com esmero para agradar ao santo, e ouso dizer que ingredientes como o amor, a alegria e a receptividade são os temperos que deixam tudo mais vívido. Falar sobre a 
comida quilombola é essencialmente falar sobre a afetividade (SILVA, 2019, p. 37).

\section{Conclusão}

Ao analisar as influências da culinária africana na formação cultural brasileira, fica evidente o seu protagonismo em diversas frentes conteporâneas. Os fatores relevantes desta influência cultural têm um importante papel na construção e valorização da cidadania de um povo, permitindo a socialização e a interação de diferentes saberes culturais. Estas manifestações presentes no multiculturalismo brasileiro são encontradas em contexto sociocultural impregnados na cultura africana há décadas.

A culinária africana, por sua vez, tem um papel importantíssimo para o processo de formação e identidade da cultura brasileira, pois a introdução de suas práticas e seus costumes contribuíram para a formação desta identidade miscigenada e tipicamente afro-brasileira. Em virtude dos fatos mencionados e disseminados em vários seguimentos da sociedade brasileira, tais como a culinária, as práticas religiosas, as danças, a música e muitos outros valores culturais que foram incorporados pela população colonial e que tornam o Brasil um país único.

E a construção da carga cultural brasileira é produto da miscigenação do nosso povo, em especial a influência da culinária africana. E esta contribuição torna-se relevante para valorização dos povos africanos neste e outros processos de integração, contribuindo para o processo constituinte de formação da identidade cultural brasileira, pois a cultura afrodescendente é que torna o nosso país uma nação multicultural de todas as cores e sabores.

\section{Referências}

ALBUQUERQUE FILHO, Heitor Freire de. A cultura nordestina e o forró de pé de serra: o caso do Projeto Cultural Museu do Vaqueiro e Forró da Lua. 2018. 51f. Trabalho de Conclusão de Curso (Graduação em Turismo), Departamento de Turismo, Universidade Federal do Rio Grande do Norte, Natal, 2018.

ALVES, Leonardo de Carvalho; DE CARVALHO, João Victor Caetano; COELHO, Maria Carlota de Rezende. A Importância da educação e da história na trajetória dos movimentos negro e indígena brasileiros e a luta destes pela re avaliação do papel do negro e do indígena na história do Brasil. In: Anais do Congresso Africanidades e Brasilidades. 2018. v. 1, n. 1, Vitória-ES, 2018. 
ANDRADE, Maria Margarida de. Introdução à metodologia do trabalho científico: elaboração de trabalhos na graduação. 10. ed. São Paulo: Atlas, 2018.

AZEVEDO, Fernando. História de minha vida: Rio de Janeiro: José Olympio, 1971.

BALDUINO, Grazielle Eloísa; SOUZA JUNIOR, Arlindo José de; SILVA, Iraides Reinaldo da. Educação de Jovens e Adultos na Cultura Digital. Informática na Educação: teoria e prática, Porto Alegre, v. 17, n. 2, p. 167-176, jul./dez. 2014.

BATALHA, Lenomar Nogueira; SILVA, FM da. Influência cultural africana: danças, jogos e brincadeiras na educação básica em Parintins/AM. Realize, Campina Grande, v. 1, e. 4, p. 1$11,2015$.

BOTELHO, Adriano. Geografia dos sabores: Ensaio sobre a dinâmica da cozinha brasileira. Revista Sabores do Brasil, v.1, n. 13, p. 61-69. 2010.

BOTELHO, Denise; DA CONCEIÇÃO SANTOS, Francineide Marques. MULHERES NEGRAS: gênero e gastronomia afro-religiosas. Caderno Espaço Feminino, v. 29, n. 1, p. 143-154, 2016.

BOURDIEU, Pierre. La distinction. Paris: Minuit, 1979.

BRASIL. Lei $n^{\circ} .10 .639$ de 09 de janeiro de 2003. Inclui a obrigatoriedade da temática "História e Cultura Afro-Brasileira" no currículo oficial da rede de ensino. Diário Oficial da União, Brasília, 2003.

BRAUNE, Renata et al. O que é Gastronomia. Brasiliense, 2017.

CASCUDO, Luís da Câmara. História da Alimentação no Brasil. São Paulo, editora Global, 2004.

CASTRO, José Valter. A memória narrada por jovens do ensino médio na significação do patrimônio cultural. 2017. 121 f. Dissertação (Pós-Graduação em Educação) - Universidade Federal de Sergipe, São Cristóvão, 2017.

CAVIGNAC, Julie Antoinette; SILVA, Danycelle. Sabores E Práticas Culinárias Das Cozinheiras Negras Do Seridó (RN-BRASIL). Revista GeoNordeste, v. 1, n. 2, p. 20-40, 2019.

COSTA, Rute Ramos da Silva; LIMA, Debora Silva do Nascimento; SILVA, Giselle Maria da; RIZZO, Tamiris Pereira; PINTO, Thatiana de Jesus Pereira. Culinária afro-brasileira: um sabor possível na Educação de Jovens e Adultos. Cadernos Cenpec, São Paulo, v. 9, n. 1, p. 75-99, jan./jul. 2019

DA SILVA, Carmelio Ferreira. A contribuição da cultura afrodescendente para o samba como parte da identidade musical brasileira. Vozes, Pretérito \& Devir: Revista de história da UESPI, v. 6, n. 1, p. 216-233, 2017.

DA SILVA, Elizabeth de Jesus. Desafios para o Ensino da Cultura e História da África: Experiências com Jogos Africanos em Escolas Públicas. Novos Olhares Sociais, v. 1, n. 1, p. 186-212, 2018. 
DA SILVA, Helder Kuiawinski. A Cultura Afro como Norteadora da Cultura Brasileira. PERSPECTIVA, v. 38, n. 144, p. 25-35, dezembro, 2014.

DA SILVA, Victor Andrade. A Importância da Plantation Açucareira no Brasil Colonial. Repositório de Trabalhos de Conclusão de Curso, v. 1, n. 1, p. 2-15, 2019.

DE CASTRO NETO, Antônio Gomes; LEITÃO, Mirtiline Pereira de Oliveira. O legado musical de Carmen Miranda e a identidade gastronômica brasileira. Revista de Humanidades, v. 29, n. 2, p. 359-373, 2014.

DE LIMA, Maria de Fátima Farias. Imagens Regionais e Restaurantes Temáticos: Comida, Cultura e Lugar. 2010. 123f. Dissertação (Mestrado em Sociologia) - Universidade Federal do Ceará, Fortaleza, Ceará, 2010.

DOS SANTOS, Carlos Roberto Antunes. A comida como lugar de história: as dimensões do gosto. História: Questões \& Debates, Curitiba, v. 1, n. 54, p. 103-124, jan./jun. 2011.

DOS SANTOS, José Luiz. O que é cultura. São Paulo - SP, Editora Brasiliense, 1998.

DO VALE, Johnatan Ferreira Marques. Religião e saúde: relações entre a umbanda e a medicina nas práticas de cura, 2013. 121f. Dissertação (Mestrado em Sociologia).

Universidade Federal da Paraíba, João Pessoa - PB, 2013.

FERREIRA, Carla Beatriz Guedes. Feijoada Carioca: Um estudo de caso sobre a modificação dos Patrimônios Culturais Imateriais, 2017. 101f. Dissertação (Mestrado em Museologia e Patrimônio). Universidade Federal do Estado do Rio de Janeiro / Programa de Pós-graduação em Museologia e Patrimônio, Rio de Janeiro, 2017.

FERREIRA, Márcio Carvalho C. A influência africana no processo de formação da cultura afro-brasileira. 2018. A cor da cultura, Disponivel em: http://www.acordacultura.org.br/artigos/29082013/a-influencia-africana-no-processo-deformacao-da-cultura-afro-brasileira, acesso em 18 de maio de 2020.

FREYRE, Gilberto. Casa grande e senzala. 51ª Ed. São Paulo: Global Editora, 2006.

GAMA, Ligia Barros; PITTA, Perin Rocha Danielle. Kosi ejé kosi orixá: simbolismo e representações do sangue no candomblé. 2009. 127p. Dissertação (Mestrado). Programa de Pós-Graduação em Antropologia, Universidade Federal de Pernambuco, Recife, 2009.

GARCIA, Rosa Wanda Diez. Representações Sociais da Comida no Meio Urbano: algumas considerações para o estudo dos aspectos simbólicos da alimentação. Revista Cadernos de Debate, v. 2, n. 1, p. 12-40,1994.

GERHARDT, Tatiana Engel; SILVEIRA, Denise Tolfo (Org.). Métodos de pesquisa. Coordenado pela Universidade Aberta do Brasil - UAB/UFRGS e pelo Curso de Graduação Tecnológica - Planejamento e Gestão para o Desenvolvimento Rural da SEAD/UFRGS. Porto Alegre: Editora da UFRGS, 2009.

GOMES, C. A. Quinze anos de ciclos no ensino fundamental: uma análise dos percursos. Revista Brasileira de Educação, v.1, n. 25, p. 39-52, jan./abr. 2004. 
GONÇALVES, Maria Alice Rezende. A Feira das Iabás em Madureira/Rio de Janeiro: comida, música e cultura afro-brasileira. Patrimônio e Memória, Assis, SP, v. 15, n. 1, p. 200219, jan./jun. 2019.

GUILHON, Flavio; SALAS, Luiza Franklin. Valorizando os saberes tradicionais de Candomblé - Uma estratégia de combate a intolerância religiosa. In: Anais do Congresso Africanidades e Brasilidades. 2016.

HARGER, Patricia Helena Campestrini. O Segmento de Moda Afro-Brasileira: conceitos, estruturas e narrativas. Moda Palavra e-periódico, v. 9, n. 18, p. 96-120, 2016.

KHATOUNIAN, Carlos Armênio et al. Produção de alimentos para consumo doméstico no Paraná: caracterização e culturas alternativas. Londrina: Iapar, 1994.

LAKATOS, Eva Maria; MARCONI, Marina de Andrade. Fundamentos de metodologia científica. 8. ed. São Paulo: Atlas, 2019.

LEME, Adinéia da Silva. Cultura Afro-Brasileira: As Contribuições da Cultura AfroBrasileira na Formação da Identidade Cultural do Povo Brasileiro. Revista Psicologia \& Saberes, v. 4, n. 5, p. 1-56, 2015.

LIMA, Kédma Cristina Costa; DA SILVA, Silvia Avelina Ribeiro; CEZAR, Valdete Alves. A Vestimenta como Símbolo de Identidade Cultural Afro-Brasileira. Revista Coletivo SECONBA, v. 1, n. 01, p. 21-32, 2017.

LIMA, Romilda de Souza; FERREIRA NETO, José Ambrósio; FARIAS, Rita de Cássia Pereira. Alimentação, comida e cultura: o exercício da comensalidade. DEMETRA: Alimentação, Nutrição \& Saúde, v. 10, n. 3, p. 507-522, 2015.

LIMA, Vivaldo da Costa. A anatomia do acarajé e outros escritos. Salvador: Corrupio, 2010.

LODY, Raul Giovanni da Motta. Joias de Axé: fios de contas e outros adornos do corpo: a joalheria afro brasileira. Rio de Janeiro: Bertrand Brasil, 2001.

LODY, Raul. Dendê. Revista Brasileira de Gastronomia, v. 1, n. 1, p. 18-33, 2018.

LODY, Raul. No tabuleiro da baiana tem... pelo reconhecimento do acarajé como patrimônio cultural brasileiro. In: GONÇALVES, José Reginaldo Santos e outros. Alimentação e cultura popular. Rio de Janeiro: Funarte, CNFCO, 2002. p. 37- 40.

LODY, Raul. Coco: comida, cultura e patrimônio. Editora Senac São Paulo, 2019.

LONGHURST, Alan R.; PAULY, Daniel. Ecologia dos oceanos tropicais. Edusp, 2007.

LONTRA, Hilda OH. Visão de fora: identidade cultural brasileira no contexto da copa do mundo de 2014. Comunicaciones en Humanidades, v.1, n. 4, p. 297-310, 2017.

LOPES, Goya; FALCON, Gustavo. Imagens da Diáspora Bahia: Solisluna Editora, 2010.

MASCARIN, Tereza Fatima. Alguns aspectos sobre alimentação: ênfase a contribuição do negro no período colonial. Revista Espaço Acadêmico, v. 15, n. 171, p. 61-68. 2015. 
MEDEIROS, Letícia Miranda; DA FONTOURA, Helena Amaral. O desafio de ensinar língua inglesa na Educação de Jovens e Adultos. Revista de Educação Popular, v. 16, n. 1, p. 82-91, 2017.

MENDONÇA, Gardênia Serafim de. et. all. A Cozinha Baiana e a Influência da Cultura Africana em sua Composição. Revista Pensar Gastronomia, v. 1, n. 2, p. 1-13, jul. 2015.

MIRA, Maria Celeste. Do recalque ao realce: o enegrecimento da cultura popular brasileira e o jogo político das identidades. Revista Pós Ciências Sociais, v. 14, n. 28, p. 19-40, 2017.

MIRANDA, Ricardo. Série Mesa Brasileira. Anais do Seminário Gastronomia em Gilberto Freyre, 2003.

MORAES, Alice da Silva et al. INFLUÊNCIA AFRO-BRASILEIRA NA MÚSICA E NA DANÇA. Revista Expressão, v. 1, n. 1, p. 27, 2020.

MORAIS, Caroline Cristina Borges de. A influência afro-brasileira na moda contemporânea através da estamparia têxtil. 2017. 92 f. Trabalho de Conclusão de Curso (Graduação em Design de Moda) — Universidade Tecnológica Federal do Paraná, Apucarana, 2017.

MULLER, Silvana Graudenz; AMARAL, Fabiana Mortimer; REMOR, Carlos Augusto. Alimentação e cultura: preservação da gastronomia tradicional. Anais do VI Seminário de Pesquisa em Turismo do Mercosul. Caxias do Sul, 2010.

NASCIMENTO, Abdias. O quilombismo. Editora Perspectiva SA, 2020.

OLIVEIRA, Luiz Felipe Mendes. Sabores do Brasil: A Ludicidade como ferramenta de Ensino-Aprendizagem sobre Patrimônio Cultural, Educação para o Turismo e Gastronomia Nacional. Revista Turismo \& Cidades, v. 1, n. 2, p. 41-61, 2020.

PARDIM, Cristiane Matos Costa; CALADO, Moacyr Cerqueira. O Ensino da Matemática na EJA: Um Estudo sobre as Dificuldades e Desafios do Professor. Revista IFES Ciência, v. 2, n. 1, p. $98-123.2016$.

PÉREZ, Xerardo Pereira. Turismo Cultural: Uma visão antropológica, El Sauzal Tenerife. España: ACA y PASOS, RTPC. 2009.

REALE, Miguel. Paradigmas da cultura contemporânea. Editora Saraiva, 2017.

RIBEIRO, Carlos Clei Simas. Educação de jovens e adultos-desafios do professor de língua portuguesa do ensino médio em uma escola da rede estadual de Parintins. 2019.

SANTOS, Gilson Graciano dos. Influências africanas na Bahia: religiões e línguas. 2017. 37f. Trabalho de Conclusão de Curso (Bacharelado em Humanidades) - Instituto de Humanidades e Letras, Universidade da Integração Internacional da Lusofonia AfroBrasileira, São Francisco do Conde, 2017.

SANTOS, V. J. O acarajé e os estudos sobre a cozinha baiana: breve revisão bibliográfica. I Seminário Alimentação e Cultura da Bahia, (pp. 2-3). Salvador, 2012.

SARAIVA, Emmanuel De Jesus. A Influência Africana na Cultura Brasileira. Clube de Autores (managed), 2016. 
SCISÍNIO, Alaor Eduardo. Dicionário da escravidão. L. Christiano Editorial, 1997.

SILVA, André Vicente e. Comida de santo: resistência e representação do sagrado pela culinária. 2016. 20f. Trabalho de Conclusão de Curso (Especialização em História e Cultura Africana e Afro-brasileira). Departamento de História do CERES - Campus de Caicó, Universidade Federal do Rio Grande do Norte. Caicó, 2016.

SILVA, Jackeline Maria da. Afro paladar: a culinária quilombola de Mato Grosso como patrimônio cultural imaterial. 2019. 51f. Trabalho de Conclusão do Curso (Especialização em Educação e Patrimônio Cultural e Artístico) - Universidade de Brasília, Brasília, 2019.

SILVA, Jeusamir Alves. Da história negada a luta por uma visibilidade igualada. Periferia, v. 10, n. 1, p. 202-212, 2018.

SILVA, Helânia Pereira da; RIBEIRO, Tereza Cristina de Farias Silva. Introdução à pesquisa. Macaíba: UFRN, 2014.

SOUSA JUNIOR, Vilson Caetano de. Na palma da minha mão: temas afro-brasileiros e questões contemporâneas. Salvador: EDUFBA, 2011. 